\title{
LEXICON
}

Volume 7, Number 2 (October 2020)

Pages 190-199

https://jurnal.ugm.ac.id/lexicon

https://doi.org/10.22146/lexicon.v7i2.66568

\section{Unreleased Bursts of Final Stops in English Words Pronounced by Native Speakers of Javanese from Yogyakarta}

\author{
Muhammad Furqon Abrori, Aris Munandar* \\ English Department, Universitas Gadjah Mada, Indonesia \\ *Corresponding Author: arismunandar@ugm.ac.id
}

\begin{abstract}
This research investigates how native speakers of Javanese from Yogyakarta realize final stops in English words, how often native speakers of Javanese from Yogyakarta pronounce final stops in English words with audible release burst, and whether release burst in final stops is a feature of Yogyakartan Javanese accent of English, based on the frequency of their occurrence. 20 native Javanese speakers from Yogyakarta, selected based on convenience, were asked to pronounce 24 English words ending in stops: /p/, /t/, /k/, /b/, /d/, and /g/. The recordings were then analyzed and compared against recordings of the words produced by native English speakers using Praat (Boersma \& Weenink, 2019) to identify the release bursts. The findings show that release burst can be found in 7 out of $80(8.75 \%)$ recordings of words ending in final /p/, 8 out of 80 (10\%) recordings of words ending in final /t/, 15 out of $80(18.75 \%)$ recordings of words ending in final /k/, 10 out of $80(12.5 \%)$ recordings of words ending in final /b/, 9 out of $80(11.25 \%)$ recordings of words ending in final /d/, and 16 out of 80 (20\%) recordings of words ending in final /g/. In total, 165 out of 480 (13.54\%) recordings contain release bursts in the final stops.
\end{abstract}

Keywords: final stops; Javanese; release burst; stops; Yogyakarta.

\section{INTRODUCTION}

In English, most visibly in dialects under the umbrella term American English and British English - the two most popular varieties of Englishthe obstruents $/ \mathrm{p} /, / \mathrm{t} /, / \mathrm{k} /$, along with their voiced counterparts, in codaic or final position are normally pronounced with an audible burst (of release) following their occlusion. Some of the names for this phonological process include 'plosion', 'release burst', and 'stop burst', among many others. Laver (1994) used all three terms interchangeably to refer to release bursts. On the contrary, the same consonants are sometimes realized as stops with no audible release (indicated by the IPA diacritic 7 ). This phenomenon is known as 'unreleased burst'. In the aforementioned American and British varieties of English, this phonological phenomenon would be deemed as highly irregular. This research attempts to examine whether or not released burst is a feature of Yogyakartan Javanese accent of English. Since this research operates on the level of phonetics-and to some extent, acoustic phonetics - the focal object of the study is the actual realization of the final stops $/ \mathrm{p} /, / \mathrm{t} /, / \mathrm{k} /, / \mathrm{b} /, / \mathrm{d} /$, and $/ \mathrm{g} /$ in English words, by native speakers of Javanese from Yogyakarta.

There have been studies on the Javanese language in the past on many subfields of linguistics, 
e.g. Brakel (1969), dealing with syntax, and SmithHefner (1989), in the subfield of historical sociolinguistics. Nevertheless, little has been done to deal with the Javanese accent of English-some of which will be described in much detail in the literature review section. Furthermore, to the best of our knowledge, none has discussed the topic of release bursts (or the lack of it), especially using the Yogyakartan variety of Javanese as the subject. This has led us to focus on unreleased burst of final stops in English words produced by native speakers of Javanese from Yogyakarta.

In particular, in this research we attempt to address the following questions:

1. How do native speakers of Javanese from Yogyakarta realize final stops $(/ \mathrm{p} /, / \mathrm{t} /, / \mathrm{k} /, / \mathrm{b} /$, $/ \mathrm{d} /$, and $/ \mathrm{g} /$ ) in English words?

2. How often do native speakers of Javanese from Yogyakarta pronounce final stops in English words with audible release bursts?

In accordance with these research questions, this research focuses on examining the pronunciation of native speakers of Javanese from Yogyakarta in pronouncing English words, which was used as the data source for this research. More specifically, the focus of the study is the speakers' pronunciation of final stops, where the phenomenon of release burst can be examined.

\section{LITERATURE REVIEW}

It is difficult to pinpoint the exact work in which the phenomenon of release burst (or the lack of it) was first studied. Nevertheless, we believe that Malecot (1958) could have been the first attempt at observing release bursts - rather, it was referred to as simply 'release' - in final stops, more specifically their roles in the identification of final stops. Later, the necessity for a specific diacritic indicating the absence of release burst was recognized. In 1976, the diacritic for the absence of release burst was approved, but it was only in 1989 (Kiel Convention) revision of the International Phonetic Alphabet under the name The International Phonetic Alphabet (revised to 1989) when the diacritic was finally mentioned for the first time.
The first work to be mentioned in this paper is a journal article titled "TH-fronting: the Substitution of $f / v$ for $\theta / \partial$ in New Zealand English" by Wood (2003) from the University of Canterbury, taken from New Zealand English Journal 2003. Although the article discusses Th-fronting, a distinct, unrelated topic from release burst, it discusses a phonological phenomenon nonetheless, and therefore, we find it very relevant. The presentation of the findingsprimarily the tabulation and statistics - is simple, yet solid. For this reason, the presentation of the results is, to some extent, modeled after the work. The methodology, however, differs to a considerable degree.

The second work is about release burst, and it might help to give an insight on how a research on release burst is done. It is an article titled "Release Bursts in English Word-Final Voiceless Stops Produced by Native English and Korean Adults and Children" by Tsukada et al (2004). The research employed noticeably more advanced, in-depth and technical analyses — and statistics — for release bursts, and is much more restrictive; the subjects chosen for the research had to fulfill several criteria and only voiceless stops are examined. The paper also, to some extent, focuses on second language (L2) acquisition on children.

The last work is an article titled "The Influence of Brebes Javanese Dialect Toward Students' Pronunciation of English Speech Sounds (A Case Study in SMAN 1 Brebes)" by Rahmatika et al (2017) taken from the 1st ELLiC Proceedings: 'Innovation, Trends, and Challenges in English Language Learning in the 21st Century'. Compared to the other two, this work is more specific, focusing on the Brebes dialect of Javanese instead of the Javanese language in general. The article attempts to describe [sic] English phonemes that are influenced by the Brebes dialect of Javanese, and describe "the teachers' roles in the development of the students' pronunciation." The results showed that all 20 participants could not pronounce the vowel [I] and instead replaced it with [i] or [i:]. Accordingly, the diphthongs [eI], [aI], [эr], and [гə] were instead realized as $[\mathrm{ei}],[\Lambda \mathrm{i}]$, [pi], and [iə], respectively. Consonants-wise, [b], [d], [g] sounds from the Brebes dialect were carried over into their pronunciations, therefore the sounds were correctly pronounced as $[\mathrm{b}],[\mathrm{d}],[\mathrm{g}]$, and not devoiced into $[\mathrm{p}],[\mathrm{t}],[\mathrm{k}]$ like 
Ramelan (1977) suggested. The clusters/st/,/spr/, and /str/ were pronounced correctly, not affected by the Brebes dialect of Javanese. The results also suggested that "the student's native language plays a role in influencing the student's difficulty in pronouncing English words" (p. 193).

This research differs by concentrating on the Yogyakartan dialect of the Javanese language and specifically delving into the (acoustic) phonetic level in analyzing the pronunciations, limited to voiceless and voiced stops /p/,/t/, /k/, /b/, /d/, /g/, and focusing on the phenomenon of release burst.

\section{THEORETICAL FRAMEWORK}

Stops, also known as plosives, are consonants formed with a complete restriction of airflow in the place of articulation. One property of stops, according to Odden (2005, p. 32), is that stops can be (optionally) followed by a release burst, or plosion, for which the restriction is "released", continuing the airflow and thus producing a burst of noise. The word plosive, therefore, refers to stops followed by a release burst. Plosives include, but not limited to, /p/, /t/, /k/, /b/, /d/, and /g/. Ramelan (1977) proposed three phases in a production of plosives:

1. Closure phase, in which two articulators are drawn together to the point of complete obstruction,

2. Stoppage phase, in which the articulators are completely obstructed, thus air cannot pass out of the mouth,

3. Release phase, in which the two articulators are separated so that they create a plosive sound.

This research focuses on the second and third phases only.

When a consonant is released, there is a delay between the stoppage phase and the release burst, which can vary due to various factors. Commonly measured in milliseconds, release burst delay is one of the many parameters that can be used to compare the release bursts produced by Javanese native speakers from Yogyakarta to the ones produced by native English speakers. To measure the delay between the stoppage and the release stage of the release burst, we utilized Praat (Boersma \& Weenink, 2019).

It is absolutely necessary to mention that with final $/ \mathrm{b} /, / \mathrm{d} /$, and $/ \mathrm{g} /$, it is impossible to discuss the release bursts (or lack thereof) without first acknowledging and understanding the phenomenon of final devoicing, also known as terminal devoicing. First observed in German and Dutch, final devoicing was made popular by Brockhaus (1995) in his book Final Devoicing in the Phonology of German. Crowley \& Bowern (2010, p. 42) wrote: "Sounds at the end of a word, especially stops and fricatives (but sometimes also other sounds, even vowels), often change from being voiced to voiceless." Ramelan (1977) claimed that words ending in /b/, /d/, and /g/ are pronounced as voiceless stops by Indonesians and Javanese speakers.

The methods and the methodology (for the data collection) in this research are based heavily on the linguistic field methods described in Introduction to Linguistic Field Methods (Vaux and Cooper, 1999) with some modifications; namely a computer instead of a tape recorder, and the use of Praat (Boersma \& Weenink, 2019) for acoustic phonetics analysis. This research uses $T H$-fronting. the Substitution of $\mathrm{f} / \mathrm{v}$ for $9 / 0$ in New Zealand English by Wood (2003) from the University of Canterbury as one of the main references; and the presentation (the statistics and the tabulation in the results section) is modeled after the paper.

Since the analysis also encompasses Javanese phonology, for transcribing the native speakers' pronunciations, we utilized the Javanese consonants and vowels charts from Concise Encyclopedia of Languages of the World by Brown and Ogilvie (2008) as the assumption for the native speakers' phoneme inventory. While the variety of Javanese used for the charts is not specified in the book-instead referred to as "Standard Javanese", we believe that they are sufficiently representative of a Yogyakartan Javanese speaker's phoneme inventory. As for the transcriptions of native English speakers' pronunciations, they are taken directly from Wiktionary's 'pronunciation' section.

Additionally, since this paper deals mainly with phonetics and phonology, the use of the International Phonetic Alphabet (in particular, the 2005 revision) is employed here in transcriptions. 
Following the 1989 IPA chart, stops with no audible release are indicated with the diacritic $?$.

\section{METHODS}

The research utilized convenience sampling in order to save time and energy. We selected the subjects based on convenience. The subjects chosen to participate in this research all must fulfill the following criteria:

1. The subject must be from Yogyakarta.

2. The subject must speak Javanese as their native language or L1.

3. The subject must have at least 12 years of education (equivalent to SMA or senior high school).

The first and second criteria were set in accordance with the title and topic of the research, while the third criterion was set so that the subjects would have had enough exposure to the English language-be it formally (from school) or nonformally-to be able to pronounce (the most common) English words with minimum difficulties. It is necessary to note that the third criterion also implies that the subjects are expected to be at least 15 years old.

While age, gender, and socio-economic status may be influential in their pronunciations, this research does not factor the aforementioned criteria into the equation, and as such, we believe further research is needed. To avoid possible bias(es), the subjects were not given any information about the research beforehand.

Using a microphone, Discord software (whenever it was required, otherwise we utilized the conventional recording method), and Audacity ${ }^{\circledR}$ software, the participants were then asked to pronounce a string of words taken from this predetermined set of words, ending in $/ \mathrm{p} /, / \mathrm{t} /, / \mathrm{k} /, / \mathrm{b} /$, /d/, and /g/:

$$
\text { up, deep, drop, step }
$$

that, right, wait, great

$$
\begin{aligned}
& \text { make, like, look, black } \\
& \text { job, grab, tube, globe, } \\
& \text { dead, good, side, head, } \\
& \text { drug, big, leg, egg }
\end{aligned}
$$

The majority of the words above were taken from the 1000 most common words list retrieved from 1000mostcommonwords.com (n.d), which claims to be based on "language experts from all over the world". The words were selected to ensure the participants' familiarity with the words-especially, how they are pronounced-and (if possible) minimize pronunciation errors or mistakes. The words are all monosyllabic and contain no consonant clusters in coda position for easier analysis.

The words were then jumbled, producing a long string of words, with the intention of making it more or less random and obscuring the pattern. They were deliberately made so that the final consonant in a word and the first consonant in the next word are in contrast with one another. We believe this model is able to obtain randomness and closely mimic actual, natural speech. Eventually, the participants were asked to pronounce this particular string of words in sequential order:

leg up job side like grab that deep drug egg head dead make globe good right big black drop tube step great look wait

Since no time constraints (in the form of words per minute limit) were involved, the participants were allowed to pronounce the words slowly and carefully. The words are supposed to be pronounced with pauses between them (as opposed to pronouncing it as one whole-if ungrammaticalsentence). It is also necessary to note that there was only one recording take/session for each subject, provided that there was no loud, interfering background noises or other unforeseen occurrences.

Afterwards, using Audacity ${ }^{\circledR}$, the recordings (containing one long list of words) were split into one audio file per word, totaling 24 words times the number of participants.

The audio files were then put into Praat (Boersma \& Weenink, 2019), producing spectro- 
grams and waveforms to be further analyzed. The Praat analysis includes (phonetic) transcription, voicing, delay of release burst (in milliseconds), aspiration, and voice onset time. During the analysis process, pronunciations taken from Wiktionary were used to compare the participants' pronunciations with pronunciations of the same words by native speakers of English-mostly BrE and AmE. Some recordings had the noise reduction filter applied.

After the release bursts were identified, the data were then separated into two: those which contain release bursts in the final stop, and those which do not. The final calculation is the number of words containing release bursts per total number of words pronounced (with or without release burst), in the form of percentage.

\section{RESULTS AND DISCUSSION}

For this research, there were 20 participants in total-all of which are hence referred to by Speaker 1 through 20-who pronounced all the 24 words. 15 of them were recorded with the researchers' own recording equipment; a dbE GM200 headphone. However, the other 5, namely Speaker 4, Speaker 5, Speaker 13, Speaker 15, and Speaker 16, were recorded online via the Discord software as they were not residing in Yogyakarta during the data collection period. Furthermore, the 5 speakers did not utilize the researchers' recording device nor the researchers' audio configuration. Therefore, it is absolutely necessary to be made clear here that some recordings had inferior audio quality, which made analysis more difficult at times.

In order to give a broader perspective, the researchers decided to use recordings of the word produced by native English speakers who, according to the audio metadata, presumably speak American English, British English, and Australian English. These recordings were taken from the internet, more specifically, from Wiktionary. The voices are attributed to Judith Franck, Celestianpower, D3VIL, and Back ache (British English), Dvortygirl (American English), and Commander Keane (Australian English). The recordings were used to compare the participants' release burst to release bursts produced by a native English speaker.
Release burst delay is one of the many parameters that one can use to compare the release bursts produced by Javanese native speakers from Yogyakarta to the ones produced by native English speakers. To measure the delay between the stoppage and the release stage of the release burst, the researchers utilized Praat. To be more exact, the researchers measured the distance or length of the area with low energy density - a period of silence between the stoppage and the release-in the final consonant in the spectrogram. This procedure was facilitated with Praat's formant and pitch detection, which is fairly reliable. Therefore, understandably, the measurement of the release burst delay is at best an approximation.

\section{Release Burst in Final /p/}

Starting with the word up, 2 of the 20 participants pronounced the word with a release burst; they are Speaker 4 and Speaker 6. Speaker 4's recording contains a release burst with a delay of 0.267506 second ( $267.5 \mathrm{~ms}$ ), while that of Speaker 6 has a longer delay of approximately 0.279392 second (279.4 ms). To put into perspective, a recording of the word up by an AuE speaker has a release burst measuring at approximately 0.101369 second (101.4 $\mathrm{ms})$.

With the next word, deep, only one recording shows the presence of a release burst. The speaker in question is Speaker 6, who pronounced the word as [d ${ }^{\text {hip] }}$, with an abnormally long release burst delay on the final $/ \mathrm{p} /$ of approximately 0.476927 second (476.9 ms). For comparison, One AuE speaker pronounced deep with a release burst delay of 0.147843 (147.8 ms), and another English speaker (presumably from Britain or France) pronounced the word with a release burst delay of approximately 0.124104 second $(124.1 \mathrm{~ms})$.

For drop, there are 2 recordings that contain a release burst in the final $/ \mathrm{p} /$; the one produced by Speaker 6 and Speaker 16. Speaker 6's release burst delay measures at 0.194002 second (194 ms) while that of Speaker 16 measures at a shroter delay of 0.115735 second $(115.7 \mathrm{~ms})$. One AmE speaker pronounced the word with a release burst delay of approximately somewhere between 0.127366 second $(127.4 \mathrm{~ms})$ and 0.089272 second $(89.3 \mathrm{~ms})$. 
The final word on the list is step. 2 out of 20 participants produced a release burst in their recording of the word step. The first one is Speaker 4, with a release burst delay of approximately 0.270544 second $(270.5 \mathrm{~ms})$. On the other hand, the release burst delay found in Speaker 6's recording measures at 0.158223 second (158.2 $\mathrm{ms})$, twice as shorter than that of Speaker 4's. For this word, one pronunciation by an AmE speaker has a release burst delay of a mere 0.79437 second $(79.4 \mathrm{~ms})$.

In total, 7 out of 80 pronunciations of the word with $/ \mathrm{p} /$ in terminal position contain release burst.

\section{Release Burst in Final / $t$ /}

With the word that, Speaker 4 produced a burst release with a comparably high delay of 0.213062 second $(213 \mathrm{~ms})$, while Speaker 6 also produced a burst release with an even higher delay of 0.307789 (307.8 ms). For the sake of comparison, one BrE native speaker's pronunciation of that has a release burst delay of 0.076882 second $(76.8 \mathrm{~ms})$

The next word, right is highly problematic, since most participants pronounced the word as /rkk/, $/ \mathrm{rch} /$ where there is no $/ \mathrm{t} /$. With that said, Speaker 4 gave a pronunciation of [..aIt] with a delay of approximately 0.114542 second (114.5 ms). Moving on, Speaker 6 also produced a release burst with a delay of 0.157437 second (157.4 ms), while that of Speaker 16 was measured at a delay of 0.135811 second (135.8 ms). An AmE speaker's release burst has a much shorter delay of mere 0.073411 second (73.4 ms).

Moving on, for the word wait, Speaker 4 produced a pronunciation of [wert] with a release burst delay of approximately 0.214642 second (214.6 $\mathrm{ms}$ ) and Speaker 16 produced a pronunciation of [weIt ${ }^{j}$ ] with a release burst delay of approximately 0.153399 second $(153.4 \mathrm{~ms})$. In contrast, one reading of wait by a native $\mathrm{BrE}$ contains a release burst delay of 0.085591 (85.6 ms).

The situation differs with great, out of the 20 readings, only one contains a release burst. The participant in question is Speaker 6-with a delay of 0.168586 second (168.6 ms). Compared to one AmE speaker, who produced a release burst with a delay of a mere $0.57504(57.5 \mathrm{~ms})$, Speaker 6's delay is almost three times as long.
All in all, the recordings indicate that 8 out of 80 words $(10 \%)$ with a final / $/$ / were pronounced with a release burst.

\section{Release Burst in Final / $\mathrm{k} /$}

There are four words with $/ \mathrm{k} /$ as the final consonant, namely make, like, look, black. With make, 3 out of 20 recordings show a presence of a release burst. The delay between the stoppage and the release measures at approximately 0.100294 second $(100.3 \mathrm{~ms})$, which is quite short for a Javanese native speaker, and the shortest so far. The next participant to pronounce make with a release burst is Speaker 6, whose release burst delay measures at 0.210872 second $(210.9 \mathrm{~ms}$ ) —although Praat stopped detecting pitch much later- which is twice as long as that of Speaker 4's. The final recording that displays a release burst is Speaker 19's pronunciation of make, and the only word pronounced by that participant to contain a release burst. The release burst delay is even longer, at approximately 0.301262 second (301.3 ms). One BrE native speaker, on the other hand, produced a release burst with a delay of about 0.95584 second $(95.6 \mathrm{~ms})$, on par with the release burst delay of Speaker 4 .

The next word analyzed is like. 4 out of 20 recordings of the word appear to contain a release burst in the final $/ \mathrm{k} /$; those are the ones by Speaker 4 , 6,15 , and 16. The delay on Speaker 4's release burst measures at 0.192202 second (192.2 ms). Speaker 6, in turn, gave a release burst delay of 0.185418 second (185.4), although the Praat pitch detection stopped earlier. The third speaker, Speaker 15, pronounced it with a release burst delay that is hard to measure due to low audio quality in recording. At best, the researchers would like to put it at 0.76344 second (76.3 ms), but this is merely relying on the researchers' auditory capability. Finally, Speaker 16's recording contains a release burst with a delay of 0.167806 second $(167.8 \mathrm{~ms})$. Comparing those release bursts against the one produced by a native English speaker-in this case, an American English speaker-which measures at 0.086929 second (86.9 $\mathrm{ms})$, the difference between Speaker 4's release burst delay and the AmE speaker's is about $10.3 \mathrm{~ms}$.

With look, the situation is very similar. Yet, one more participant i.e. Speaker 7 also produced a release burst, which is only one among the other 23 
words where an audible release burst can be found. Below are the release burst delays for each speaker:

- $\quad$ Speaker 4: 0.203971 second (204 ms)

- $\quad$ Speaker 6: 0.187658 second (188.6 ms)

- $\quad$ Speaker 7: 0.70549 second (70.5 ms)

- $\quad$ Speaker 16: 0.55272 second (55.3 ms)

One BrE speaker, in turn, produced a release burst with a measured delay of 0.232499 second $(232.5 \mathrm{~ms})$, which is noticeably longer than the ones produced by the Javanese-speaking participants.

Finally, the participants were asked to pronounce the word black. There were four participants who pronounced the «ck with a release burst, namely Speaker 4, Speaker 6, Speaker 10, and Speaker 16. Speaker 4's release burst has a delay of approximately 0.208039 second (208 ms). The next participant to release the final $/ \mathrm{k} /$ in black was Speaker 6, who produced a release burst with a delay measuring at 0.150441 second (150.4 ms). Speaker 10 's release burst delay measures at 0.201956 second (202 ms), and finally, there is Speaker 16, who pronounced the word black with a release burst delay that is hard to measure due to an echo in the recording interfering with the analysis. However, an approximation would put it at 0.092952 second (93 $\mathrm{ms})$. In contrast, a recording produced by a native BrE speaker contains a release burst measuring at a delay of 0.109256 second (109.3 ms).

For this section, there are, in total, 15 out of 80 recordings of words with $/ \mathrm{k} /$ in the final position that contain an audible release burst.

\section{Release Burst in Final /b/}

For the first word, the participants were asked to pronounce job, a word chosen due to its familiarity. Nevertheless, only 2 out of 20 recordings contain a release burst in the final $/ \mathrm{b} /$. The first participant to do so was Speaker 6, who produced a release burst with a relatively long delay of approximately 0.287901 second (287.9 ms). Moving onto the next participant, which is Speaker 16, we get another release burst delay that was difficult to measure due to the not-so-excellent audio quality, however, relying on the Praat pitch detection alone shows approximately 0.147452 second (147.4 ms) delay on the release burst. For comparison, a native
AmE speaker pronounced the word job with a release burst delay of 0.094659 second $(94.6 \mathrm{~ms})$.

What comes next is the word grab. There are 3 recordings (out of 20) that contain a release burst in the final $/ b /$, namely the ones by Speaker 6 , Speaker 12, and Speaker 16. The release burst of Speaker 6 measures at 0.258687 second $(258.7 \mathrm{~ms})$. However, moving on to Speaker 12, the delay produced by the particular speaker is - again - tricky to measure. This is due to the difficulty in determining the exact period when the closure and stoppage stage occur in the recording. As with before, Praat's pitch detection gave an account of 0.188980 second (189 ms). Finally, Speaker 16's recording has a considerably short release burst delay at - give or take- 0.133337 second (133.3 ms). One AmE speaker, for comparison, pronounced the word grab with a release burst delay of 0.094528 second (94.5 ms).

Moving on to the recordings of the word tube, the first evidence of release burst comes from Speaker 6, who released the final /b/ (or rather, /p/ since final devoicing occurs) with a delay of 0.240906 second (241 ms). Speaker 9, on the other hand, produced the release burst of the final ‘b at the same time as the production of the /s/ sound in step, the word that comes after. In other words, the pause between tube and step is very short. The aforementioned pause was treated a release burst delay, with a measure of 0.168962 second $(169 \mathrm{~ms})$. Finally, the delay of Speaker 16's release burst measures at a comparably short delay of 0.111935 second (111.9 ms). For comparison, one BrE native speaker produced a release burst in the word tube with a delay of 0.108262 second (108.3 ms).

Finally, for the final /b/ section, the participants were asked to pronounce the word globe. This word was chosen arbitrarily, but it is most definitely familiar to many people. Nevertheless, only 2 out of 20 participants pronounced it with an audible release burst: Speaker 6 and Speaker 16. The release burst found in Speaker 6's pronunciation of globe has a delay of approximately 0.344106 second (344.1 ms). For the other participant i.e. Speaker 16, there is a very weak, almost inaudible release burst. The delay is measured at 0.129081 second $(129 \mathrm{~ms})$ although the presence of echo in the recording complicates the analysis. As usual, taking one AuE 
speaker's pronunciation to compare with, the release burst measures at give or take $0.88907 \mathrm{~ms}(88.9 \mathrm{~ms})$, which is very short.

The total number of recordings for this section in which release burst is produced totals 10 out of 80 recordings (12.5\%).

\section{Release Burst in Final /d/}

Perhaps, a special caution needs to be taken for this section. There are 2 alveolar and 2 retroflex stops (both belong to the coronal category) in Javanese: $/ \mathrm{t} /$, $/ \mathrm{d} /, / \mathrm{t} /$, and $/ \mathrm{d} /$. On the other hand, the English language only recognizes $/ \mathrm{t} /$ and $/ \mathrm{d} /$, at least at a phonemic level. Therefore, English /d/ is closer to Javanese /d/ than /d/. Starting with the word dead, there are 2 recordings in which the final /d/ was released. The first one is by Speaker 4 . The release burst delay, after being measured, is 0.103682 second (103.7 ms). The other one is by Speaker 6, who produced a release burst with a long delay of 0.278596 second $(278.6 \mathrm{~ms})$. As usual, the researchers would like to compare the recordings to a recording produced by a native English speaker. In this case, they were compared to one produced by an AmE speaker. The release burst delay in her rendition of dead is hard to measure due to the difficulty in determining the stoppage stage of the second $/ \mathrm{d} /$. However, simply measuring the white-low energy-area with no F2 would yield a result of 0.087676 second $(87.7 \mathrm{~ms})$.

Moving on, we get to the word good, for which in total 2 out of 80 recordings of the word good contain an audible release burst. The delay of Speaker 4's release burst measures at approximately 0.132456 second (132.5 ms), and the next participant to pronounce it with a release burst was Speaker 16, who produced a release burst on the final /d/ with a delay of 0.126890 second (126.9 ms). To compare with, one AmE native speaker has a release burst in the word good measuring at approximately 0.76733 second (76.7 ms).

What comes next is the word side. There are 3 participants who produced a release burst for side. Starting with Speaker 4, there is a release burst with a delay of 0.162162 second $(162.2 \mathrm{~ms})$. Next, there is Speaker 6, whose recording contains a release burst with a delay of approximately 0.251841 second (251.8 ms). Finally, Speaker 16 produced a release burst with a delay of 0.173415 second $(173.4 \mathrm{~ms})$, roughly. To put into perspective, one AuE speaker produced a release burst in the word side, with a very short delay of merely 0.061956 second (62 ms).

The final word on the final/d/ list is head. Only 2 recordings contain a release burst, namely the ones by Speaker 4 and 16. Speaker 4's release burst delay measures at 0.174775 second $(174.8 \mathrm{~ms})$. The second participant to produce a release burst in the word head was Speaker 16, who produced a relatively weak release burst with a delay of approximately 0.139909 second $(140 \mathrm{~ms})$. One BrE speaker, for the sake of comparison, produced a release burst with a delay of 0.075827 second (75.8 ms).

In total, release burst can be found in 9 out of 80 pronunciations of the words ending in final $/ \mathrm{d} /$.

\section{Release Burst in Final /g/}

This section-release burst in final /g/ contains the most release burst count, totaling 16 out of all 80 pronunciations of words ending in final $/ \mathrm{g} /$. To begin, the participants were asked to pronounce the word drug, and there are 3 recordings of the word drug that contain release bursts in the final $/ \mathrm{g} /$. The first one can be found in Speaker 4's pronunciation. The release burst in question has a delay of approximately 0.163361 second (163.4 ms). Moving on, the next participant, Speaker 6 , produced a release burst with a delay of 0.208796 second (208.8 $\mathrm{ms})$. Finally, there is Speaker 16, who pronounced drug with a release burst, with the delay measuring at 0.114484 second $(114.5 \mathrm{~ms})$ although there is echo in the recording, which makes the measurement less precise. One AmE speaker, on the other hand, produced a release burst in drug with a delay of 0.102350 second (102.3 ms).

For the next word, big, there are 3 recordings containing a release burst in the final consonant. The first one is by Speaker 4, whose release is, however, rather weak. The release burst delay is approximately 0.142435 second ( $142.4 \mathrm{~ms}$ ), although the echo in the recording complicates this process, as has happened before. The next participant, Speaker 6, produced a release burst with a delay of 0.158857 second (158.9 $\mathrm{ms})$. Lastly, moving on to the final speaker, Speaker 16 , the release burst delay measures at approximately 0.099319 second $(99.3 \mathrm{~ms})$. As usual, the researchers would like to compare the recordings with one 
produced by a native English speaker, in this case an AmE speaker. The release burst produced by the AmE speaker has a delay of 0.84902 second $(84.9 \mathrm{~ms})$.

Moving on to the next word leg, 5 out of 20 participants pronounced this word with a release burst, namely Speaker 1, Speaker 4, Speaker 6, Speaker 14, and Speaker 16. Starting with Speaker 1, the release burst is very weak (yet it is the loudest one produced by Speaker 1) with a delay of 0.114690 second (114.7 ms). Speaker 4's release burst delay is about $40 \mathrm{~ms}$ longer, which measures at 0.152927 second (152.9 ms). Speaker 6's release burst, however, has a long delay, at 0.223399 second (223.4 $\mathrm{ms})$. The fourth participant to pronounce leg with a release burst is Speaker 14, whose release burst delay measures at 0.221823 second $(221.8 \mathrm{~ms})$. Finally, Speaker 16 produced a release burst with a delay of approximately 0.138316 second $(138.3 \mathrm{~ms})$. Compared to the recordings produced by the Javanese speaker, one AuE speaker pronounced leg with a release burst delay of 0.77745 second (77.7 $\mathrm{ms})$.

Last, but not least, is the word egg. When it comes to familiarity with the word egg, the researchers believe that the word is well-known to many people. As with the previous word, the participants who produced a release burst in egg amounts to 5, out of 20 participants. The first participant to do so is Speaker 4, with a release burst delay of 0.139381 second (139.4 ms). The next participant, Speaker 6, produced a release burst delay of 0.209523 second $(209.5 \mathrm{~ms})$, Next, there is Speaker 14 who, just like with leg, produced a weak release burst with a delay measured at 0.299215 second (299.2 ms). Moving on to the next speaker, Speaker 15 's recording contains a release burst that is equally weak-if not weaker-than the one produced by Speaker 14. The delay measures at approximately 0.119334 second (119.3 ms), although this is probably inaccurate due to imperfect audio quality. Finally, we get to Speaker 16, who pronounced egg as [ek], with a release burst that has a delay of 0.141823 second $(141.8 \mathrm{~ms})$. For the sake of comparison, one American English speaker produced a pronunciation of [e:g], with a release burst delay of approximately 0.99096 second (99.1 ms).
As has been mentioned before, there are 16 out of 80 pronunciations in which release burst can be found.

\section{CONCLUSION}

After analyzing a total number of 480 recordings produced by 20 Javanese-speaking participants from Yogyakarta, finding shows that for words with final voiceless stops, release burst can be found in 7 out of $80(8.75 \%)$ recordings of words ending in final /p/, 8 out of $80(10 \%)$ recordings of words ending in final $/ \mathrm{t} /$, and 15 out of $80(18.75 \%)$ recordings of words ending in final $/ \mathrm{k} /$. Overall, 30 out of $240(12.5 \%)$ recordings with final voiceless stops contain release burst.

Meanwhile, for words with final voiced stops, release burst can be found in 10 out of 80 (12.5\%) recordings of words ending in final /b/, 9 out of 80 (11.25\%) recordings of words ending in final $/ \mathrm{d} /$, and 16 out of $80(20 \%)$ recordings of words ending in final /g/. In total, 35 out of 240 (14.58\%) recordings with voiced stops in the final position contain release burst.

To conclude, per the research questions, the realizations of final /p/, /t/, /k/, /b/, /d/, and /g/ vary from speaker to speaker, yet the lack of release burst is relatively consistent. Quantity-wise, however, the native Javanese speakers from Yogyakarta produced a release burst in 65 out of 480 (13.54\%) recordings of words with final stops.

\section{REFERENCES}

1000 Most Common English Words. (n.d.).

Retrieved August 4, 2019, from https://1000mostcommonwords.com/1000 -most-common-english-words/.

Audacity Team (n.d). Audacity(R): Free Audio Editor and Recorder [Computer Program]. Retrieved August 4, 2019, from https://www.audacityteam.org/ 
Boersma, P. \& Weenink, D. (2019). PRAAT: Doing phonetics by computer, version 6.1.42,

Retrieved August 4, 2019, from https://www.fon.hum.uva.nl/praat/.

Brakel, L. F. (1969). A note on the importance of the Ngoko-Krama distinction for the determination of Javanese language structure. Bijdragen Tot De Taal-, Land En Volkenkunde / Journal of the Humanities and Social Sciences of Southeast Asia, 125, 2, 263266. doi: 10.1163/22134379-90002846.

Brockhaus, W. (1995) Final devoicing in the phonology of German. Tuibingen: Max Niemeyer Verlag.

Brown, K., \& Ogilvie, S. (2008). Concise encyclopedia of languages of the world. Burlington: Elsevier.

Crowley, T., \& Bowern, C. (2010). An introduction to historical linguistics (4th Ed.). Oxford: Oxford University Press, Inc.

Discord Inc. (n.d). Discord [Computer Software]. Retrieved August 4, 2019, from: http://discord.com.

Laver, J. (1994). Principles of phonetics. Cambridge: Cambridge University Press.

Malécot, A. (1958). The role of releases in the identification of released final stops: A series of tape-cutting experiments. Language, 34(3), 370-380.
Odden, D. (2005). Introducing phonology. New York: Cambridge University Press.

Rahmatika, D., Mujiyanto., J, \& Sukrisno, A. (2017). The influence of Brebes Javanese dialect toward students' pronunciation of English speech sounds (A case study in SMAN 1 Brebes). 1st ELLiC Proceedings: 'Innovation, Trends, and Challenges in English Language Learning in the 21st Century ', pp 189-194.

Ramelan. (1977). English phonetics. Semarang: UPT UNNES PRESS.

Smith-Hefner, N. J. (1989). A social history of language change in highland East Java. The Journal of Asian Studies, 48(2), 257-271. DOI: $10.2307 / 2057377$

Tsukada, K., Birdsong, D., Mack, M., Sung H, Bialystok E., Flege, J. (2004). Release bursts in English word-final voiceless stops produced by native English and Korean adults and children. Phonetica, 61, 67-83. DOI: 10.1159/000082557.

Vaux, B., \& Cooper, J. (1999). Introduction to linguistic field methods. München: LINCOM $\mathrm{GmbH}$.

Wood, E. (2003). TH-fronting: The substitution of $\mathrm{f} / \mathrm{v}$ for $\theta / \mathrm{\partial}$ in New Zealand English. New Zealand English Journal 2003, 17, 50-56. 